\title{
Prolonged Neural Expiratory Time Induced by Mechanical Ventilation in Infants
}

\author{
JENNIFER BECK, MARISA TUCCI, GUILLAUME EMERIAUD, JACQUES LACROIX, AND \\ CHRISTER SINDERBY \\ Pediatric Intensive Care Unit, Department of Pediatrics and Hôpital Sainte-Justine Research Center, \\ Université de Montréal, Montreal, Quebec H3T 1 C5 [J.B., M.T., G.E., J.L.]; Department of Newborn and \\ Developmental Pediatrics, Sunnybrook and Women's College Health Sciences Centre, Toronto, Ontario \\ M5S 1B2 [J.B.]; and Department of Critical Care Medicine, St-Michael's Hospital, Toronto, Ontario M5B \\ 1 W8 [C.S.], Canada
}

\section{ABSTRACT}

postmandatory spontaneous breaths $(607 \pm 268 \mathrm{~ms}$ and $560 \pm$ $227 \mathrm{~ms}$, respectively). Delivery of the mandatory breath resulted in a reduction in neural respiratory frequency by $28.6 \pm 6.4 \%$ from the spontaneous premandatory frequency. The magnitude of inspiratory electrical activity of the diaphragm was similar for all three breath conditions. For the mandatory breaths, ventilatory assist persisted for $507 \pm 169 \mathrm{~ms}$ after the end of neural inspiratory time. Infant-ventilator asynchrony (both inspiratory and expiratory asynchrony) was present in every mandatory breath and constituted $53.4 \pm 26.2 \%$ of the total breath duration. (Pediatr Res 55: 747-754, 2004)

\section{Abbreviations}

EAdi, electrical activity of the diaphragm

HB, Hering-Breuer

Pao, airway opening pressure

SIMV, synchronized intermittent mandatory ventilation

Te, expiratory time

Ti, inspiratory time
Newborn infants have strong reflexes that play a large role in the control of breathing (1). The work of Hering and Breuer in 1868 demonstrated in newborn animals that expansion of the lung reflexly inhibits inspiration-the HB inspiratoryinhibiting reflex - and promotes expiration - the HB expiratory-promoting reflex (2). With respect to mechanical ventilation in infants, it is reasonable to expect that delivery of ventilatory assistance should reflexly reduce neural $\mathrm{Ti}$ and neural inspiratory activity within the breath delivered. With respect to the HB expiratory-promoting reflex, one would expect an increase in neural Te during the assisted breath, compared with a

Received November 19, 2002; accepted October 31, 2003.

Correspondence: Jennifer Beck, M.D., 40 Humberview Road, Toronto, Ontario M6S 1W6, Canada; e-mail: jennifer.beck@rogers.com

Supported by Fonds de la Recherche en Santé du Québec (FRSQ), Canadian Intensive Care Foundation, and Fondation de l'Hôpital Sainte-Justine.

DOI: 10.1203/01.PDR.0000119368.21770.33 spontaneous unassisted breath. The expiratory-promoting reflex has been clinically observed in mechanically ventilated infants, but was described with indirect estimates of neural timing (such as airway or esophageal pressure or flow) to gauge its effects (3-5). In addition to the fact that no quantitative evaluation of the reflex was made, the recent work of Parthasarathy et al. (6) has demonstrated that indirect estimates of respiratory timing are in poor agreement with more direct measurements of neural activity.

Much of the available literature on reflex control of breathing has been derived from anesthetized healthy animals. There is only very limited information on reflex control of healthy awake humans, and virtually no information on reflex control in patients with lung disease undergoing ventilatory support (adult or pediatric). To our knowledge, there are no studies evaluating the influence of ventilatory assist on neural timing and neural activity in human infants, with direct measurements of respiratory muscle activity. 
With this background knowledge, we asked the following questions: In infants, does a single ventilator-assisted breath 1) reduce neural $\mathrm{Ti}, 2$ ) reduce the diaphragm activation, and 3) prolong neural Te within the breath delivered? To answer these questions, we studied the EAdi in infants who were breathing on the SIMV mode of mechanical ventilation. Neural timing and inspiratory EAdi were compared for three conditions: 1) the mandatory breaths, 2) the spontaneous breaths immediately preceding the mandatory breath (premandatory spontaneous breath), and 3) the first spontaneous breath after the mandatory breath (postmandatory spontaneous breath). Our hypothesis was that both the inspiratory-inhibiting reflex and the expiratory-promoting reflex would be elicited during the delivery of the mandatory breaths.

\section{METHODS}

Subjects. Fourteen patients (11 boys, three girls) with acute respiratory failure were studied. Their mean $( \pm$ SD) age, postconceptual age, height, and weight were $2.3 . \pm 1.3 \mathrm{mo}$, $35.8 \pm 4.5$ weeks, $54.3 \pm 3.4 \mathrm{~cm}$, and $3.95 \pm 0.82 \mathrm{~kg}$, respectively (Table 1). Seven of the 14 patients were born premature. The ethical and scientific committees of Hôpital Sainte-Justine, Montreal, Quebec, Canada, approved the protocol. Written informed consent was obtained from the parents of all patients. Patients were mechanically ventilated in the SIMV mode with a relatively low rate (rate, $11.2 \pm 6.5$ breaths/min) and long inflation time (754 $\pm 89 \mathrm{~ms})$. Patients had not received sedation for at least $6 \mathrm{~h}$ before the test. They were orally or nasally intubated and mechanically ventilated with a Draeger Babylog 8000 ventilator (Drager, Lubeck, Germany) with the ventilator settings as described in Table 2 . The ventilator settings had not been adjusted for $12 \mathrm{~h}$ before the test. The most sensitive trigger setting ("1") was used. The mandatory breaths were delivered with a continuous flow of 10 $\mathrm{L} / \mathrm{min}$.

Measurements. Electrical activity of the crural diaphragm (EAdi) was obtained using nine miniaturized electrodes mounted on a conventional nasogastric $(8 \mathrm{~F})$ feeding tube (Benlan Inc., Oakville, Ontario, Canada) and spaced $5 \mathrm{~mm}$ apart. Pao was measured from a side port of the endotracheal tube (Sensym Inc., Milpitas, CA, U.S.A.; $\pm 350 \mathrm{~cm} \mathrm{H}_{2} \mathrm{O}$ ). The EAdi and Pao signals were fed into a computer for data acquisition and online display. Expired volumes were noted from the ventilator display in nine of the 14 patients every minute, for both the spontaneous and the mandatory breaths. To achieve this, a stopwatch was used to monitor the time, and every minute, for the 5-min period, one of the investigators would note the first spontaneous tidal volume displayed on the ventilator monitor (on the Draeger Babylog this is displayed breath-by-breath), and then the first mandatory breath. The system for EAdi measurement was approved by Health Canada for Investigational Testing of Medical Devices.

Protocol. After endotracheal aspiration, the feeding tube with the electrodes was passed through the nose or mouth and placed such that the middle of the array of electrodes was located at the level of the crural diaphragm. Electrode positioning was achieved by online feedback of the EAdi signals (7). After insertion and placement of the catheter, the infants continued to breathe on the prescribed ventilator settings. Ten minutes after catheter placement, recordings of EAdi and Pao were obtained for a 5-min period.

Data analysis. EAdi signals were processed with algorithms as described by Sinderby et al. (8-10). The root-mean-square of EAdi was calculated and used as a measurement of EAdi signal strength. Timing and amplitudes of EAdi were evaluated for 1) the intermittent mandatory breaths, 2) the spontaneous breaths immediately preceding the mandatory breath, and 3) the first spontaneous breath after the mandatory breath. Neural Ti was arbitrarily defined as the difference in time between the onset of EAdi and the peak of the inspiratory EAdi (Fig. 1). Neural Te was arbitrarily defined as the difference in time between the peak of the inspiratory EAdi and the onset of the subsequent inspiratory EAdi (Fig. 1). Instantaneous neural breathing frequency was calculated as $60 /($ neural $\mathrm{Ti}+$ neural $\mathrm{Te})$. For quantification of signal strength, the mean inspiratory EAdi from baseline to peak (mean EAdi) and the inspiratory change in EAdi from baseline (baseline-to-peak EAdi) were calculated for the three breath conditions. For the mandatory breaths, the relative change in neural Te from the premandatory breath value was expressed as the difference between mandatory breath neural $\mathrm{Te}$ and premandatory breath neural $\mathrm{Te}$

Table 1. Patient anthropometric data and admission diagnosis

\begin{tabular}{|c|c|c|c|c|c|c|}
\hline Patient & Sex & $\begin{array}{l}\text { Age } \\
(\mathrm{mo})\end{array}$ & $\begin{array}{l}\text { Postconceptual age } \\
\text { (wk) }\end{array}$ & $\begin{array}{l}\text { Height } \\
(\mathrm{cm})\end{array}$ & $\begin{array}{l}\text { Weight } \\
(\mathrm{kg})\end{array}$ & Admission diagnosis \\
\hline 1 & $\mathrm{M}$ & 4 & 28 & 51 & 2.7 & Aspiration pneumonia \\
\hline 2 & M & 2 & 39 & 57 & 5.6 & Bronchiolitis \\
\hline 4 & M & 1 & 40 & 53 & 4.3 & Bronchiolitis \\
\hline 5 & $\mathrm{~F}$ & 4 & 36 & 60 & 4.0 & Bronchiolitis \\
\hline 6 & M & 4 & 29 & 48 & 3.7 & Subglottic stenosis \\
\hline 9 & M & 2 & 33 & 51 & 2.8 & Bronchiolitis \\
\hline 10 & $\mathrm{~F}$ & 0.5 & 40 & 58 & 4.6 & Bronchiolitis \\
\hline 11 & M & 2 & 37 & 55 & 4.5 & Viral pneumonia \\
\hline 12 & M & 1.5 & 40 & 56 & 4.3 & Bronchiolitis \\
\hline 13 & M & 3 & 35 & 55 & 4.2 & Gastroschisis \\
\hline 14 & M & 1 & 40 & 58 & 3.8 & Enterocolitis \\
\hline
\end{tabular}


Table 2. Ventilator settings

\begin{tabular}{|c|c|c|c|c|c|}
\hline Patient & $\begin{array}{l}\text { SIMV rate } \\
\text { (breaths/min) }\end{array}$ & $\begin{array}{l}\mathrm{PEEP} / \mathrm{PIP} \\
\left(\mathrm{cm} \mathrm{H}_{2} \mathrm{O}\right)\end{array}$ & $\begin{array}{l}\mathrm{FiO}_{2} \\
(\%)\end{array}$ & $\begin{array}{l}\text { Measured ventilator } \mathrm{Ti} \\
(\mathrm{ms})\end{array}$ & Days on MV \\
\hline 1 & 10 & $5 / 35$ & 40 & 750 & 4 \\
\hline 2 & 10 & $3 / 33$ & 30 & 710 & 3 \\
\hline 4 & 20 & $4 / 25$ & 35 & 830 & 7 \\
\hline 5 & 10 & $4 / 32$ & 40 & 760 & 9 \\
\hline 6 & 5 & $5 / 22$ & 30 & 960 & 9 \\
\hline 9 & 22 & $5 / 27$ & 30 & 780 & 7 \\
\hline 10 & 5 & $5 / 21$ & 25 & 680 & 3 \\
\hline 11 & 10 & $4 / 14$ & 30 & 594 & 8 \\
\hline 12 & 10 & $5 / 24$ & 30 & 747 & 8 \\
\hline 13 & 5 & $3 / 28$ & 25 & 750 & 5 \\
\hline 14 & 5 & $5 / 33$ & 25 & 707 & 13 \\
\hline
\end{tabular}

Abbreviations used: PIP, peak inspiratory pressure; PEEP, positive end-expiratory pressure; $\mathrm{Fio}_{2}$, fraction of inspired oxygen; MV, mechanical ventilation.

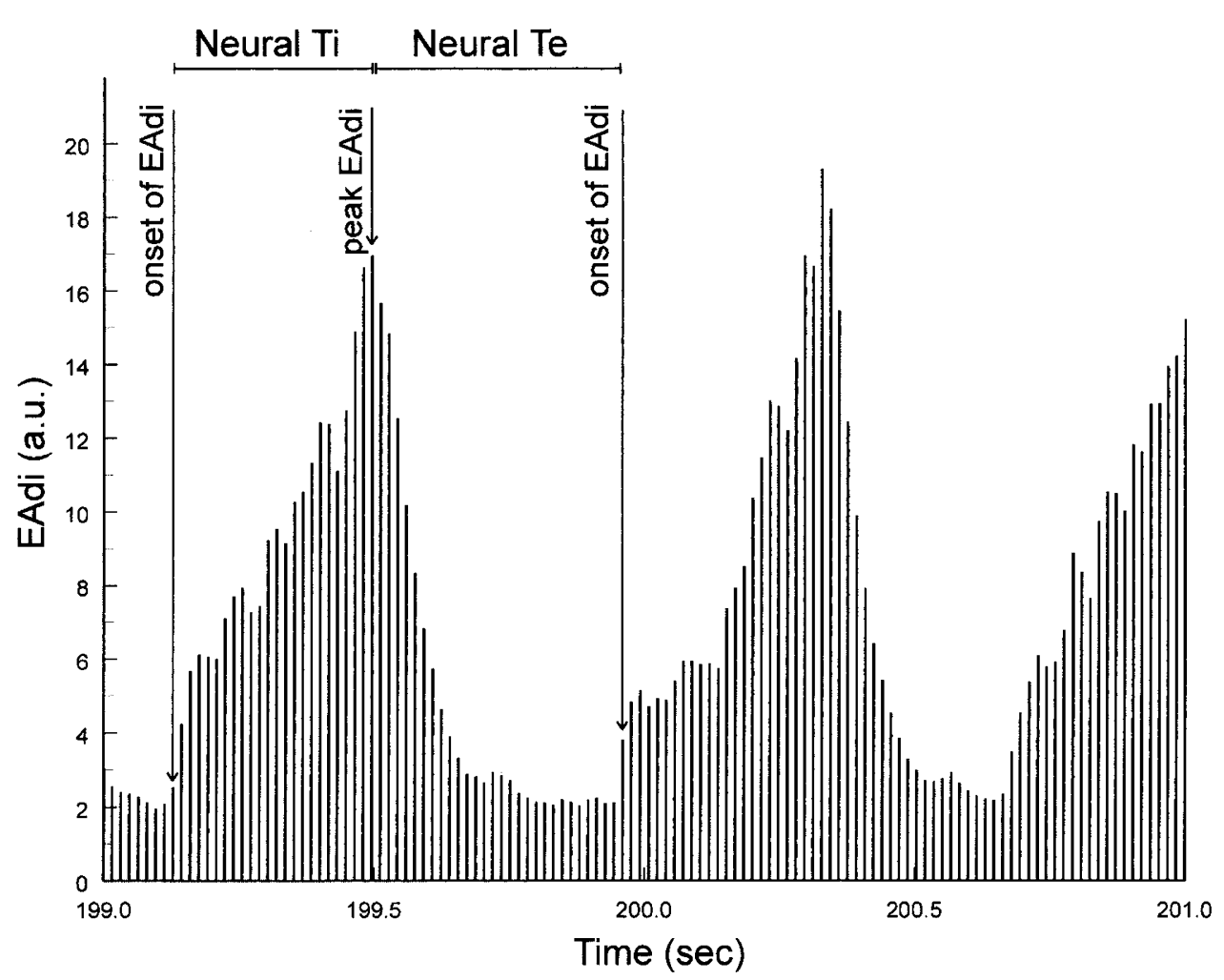

Figure 1. Neural Ti was arbitrarily defined as the difference in time between the onset of EAdi and the peak of the inspiratory EAdi. Neural Te was arbitrarily defined as the difference in time between the peak of the inspiratory EAdi and the onset of the subsequent inspiratory EAdi.

divided by the premandatory breath neural Te, then multiplied by 100 .

Statistical analysis. Statistical analysis was performed with commercially available software (Sigmastat, version 2.0; Jandel Scientific, San Rafael, CA, U.S.A.). Data in text and tables are presented as mean $\pm \mathrm{SD}$. One-way repeated-measures ANOVA was used to calculate differences in neural Ti, neural Te, mean EAdi, and baseline-to-peak EAdi among the three types of breaths. A $p<0.05$ was considered to be significant. Linear regression analysis was used to evaluate the relationship between changes in neural $\mathrm{Te}$ and the time of ventilator inflation during neural expiration. Variability was evaluated by the coefficient of variation, expressed as percent.

\section{RESULTS}

All patients tolerated the experimental protocol and insertion of the catheter. The number of breaths analyzed for the 5-min study period ranged between 6 and 25 per minute for the mandatory breaths (and postmandatory breaths), and between 8 and 48 per minute for the premandatory spontaneous breaths.

Table 3 presents the neural timing and EAdi amplitude variables for the mandatory and the premandatory and postmandatory spontaneous breaths. Neural Ti was similar for the three breath conditions $(p=0.502)$. In all subjects, neural Te was significantly increased for the mandatory breaths (953 \pm $449 \mathrm{~ms})$ compared with the premandatory $(607 \pm 268 \mathrm{~ms})$ and 
Table 3. Neural timing and EAdi amplitude for premandatory spontaneous breaths, mandatory breaths, and postmandatory spontaneous breaths

\begin{tabular}{|c|c|c|c|}
\hline & Premandatory spontaneous breath & Mandatory breath & Postmandatory spontaneous breath \\
\hline Neural Ti (ms) & $297 \pm 87$ & $331 \pm 139$ & $304 \pm 118$ \\
\hline Neural Te (ms) & $607 \pm 268$ & $953 \pm 449 * \dagger$ & $560 \pm 227$ \\
\hline Neural breathing frequency & $73 \pm 23$ & $53 \pm 18 * \dagger$ & $77 \pm 25$ \\
\hline Baseline-to-peak EAdi (a.u.) & $6.47 \pm 4.10$ & $6.82 \pm 4.11$ & $5.91 \pm 3.68$ \\
\hline Mean EAdi (a.u.) & $4.72 \pm 2.23$ & $4.70 \pm 2.23$ & $4.29 \pm 1.84$ \\
\hline
\end{tabular}

$* p<0.001$, significantly different from premandatory spontaneous breath value.

$\dagger p<0.001$, significantly different from postmandatory spontaneous breath value.

$\$ p<0.05$, significantly different from premandatory spontaneous breath value.

$\S p<0.05$, significantly different from postmandatory spontaneous breath value.

Abbreviation used: a.u., arbitrary units.

postmandatory spontaneous breaths $(560 \pm 227 \mathrm{~ms} ; p<$ 0.001). There was no difference in neural Te between the premandatory and postmandatory spontaneous breaths. The mandatory breath resulted in a reduction in neural breathing frequency by $28.6 \pm 6.4 \%$ from the premandatory spontaneous neural breathing frequency $(73 \pm 23$ breaths $/ \mathrm{min}$; Table 3$)$. Figure 2 displays the tracings of EAdi and Pao for one representative subject (patient 9), and shows how delivery of a mandatory breath causes an increase in neural Te.

With respect to inspiratory EAdi amplitude, neither mean EAdi nor baseline-to-peak EAdi was significantly different for the three breath conditions (Table 3). Figure 3 shows peak EAdi-time profiles averaged for the group during the premandatory spontaneous breaths (solid line), the mandatory breaths (dashed line), and postmandatory spontaneous breaths (dotted line). Although the diaphragm activation pattern is oversimplified in this schematic (only three points of the diaphragm activation pattern are presented), the figure indicates the sim- ilarity in inspiratory timing and inspiratory EAdi amplitude for the mandatory, the premandatory, and the postmandatory breaths, with a clear prolongation of neural Te for the mandatory breaths.

Mandatory volumes $(7.33 \mathrm{~mL} / \mathrm{kg})$ were significantly greater than spontaneous volumes $(3.8 \mathrm{~mL} / \mathrm{kg} ; p<0.001)$.

For the mandatory breaths, the mean delay between the onset of EAdi and the onset of ventilator assistance was 95 (range, $10-170 \mathrm{~ms}) \pm 39 \mathrm{~ms}$ (range, 5-110 ms). This inspiratory asynchrony (increasing diaphragm activation with no matching ventilatory assist) was equivalent to $29 \%$ of the neural Ti. A comparison of neural timing and the ventilator inflation time (which was $754 \pm 89 \mathrm{~ms}$ ) for the mandatory breaths revealed that the ventilator continued to inflate the patient for $507 \pm 169 \mathrm{~ms}$ after the end of the neural Ti (i.e. during neural $\mathrm{Te}$ ). This expiratory asynchrony period represented $53 \%$ of the neural Te. Taking both the inspiratory and expiratory asynchrony together, we found that asynchrony was

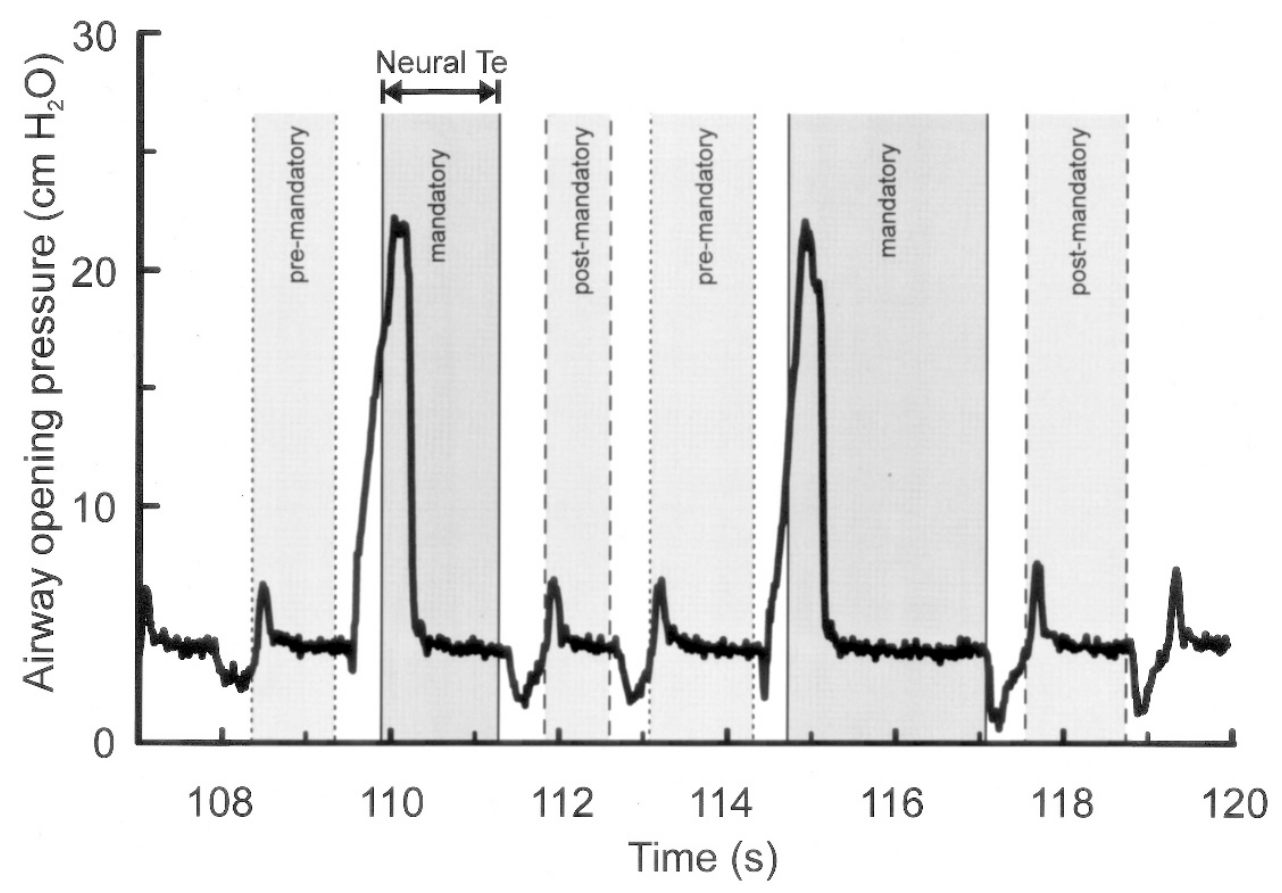

Figure 2. Tracing of Pao with corresponding neural Te in one representative subject. Pao, with shaded areas indicating corresponding neural Te period. Premandatory spontaneous breath neural Te is shaded light gray and bound by small dashed lines. Mandatory breath neural Te is shaded dark gray and bound by solid lines. Postmandatory spontaneous breath is shaded light gray and bound by long dashed lines. This example shows in one subject (no. 9) the increase in neural Te for the mandatory breaths compared with the neural Te for the premandatory and postmandatory spontaneous breaths. 


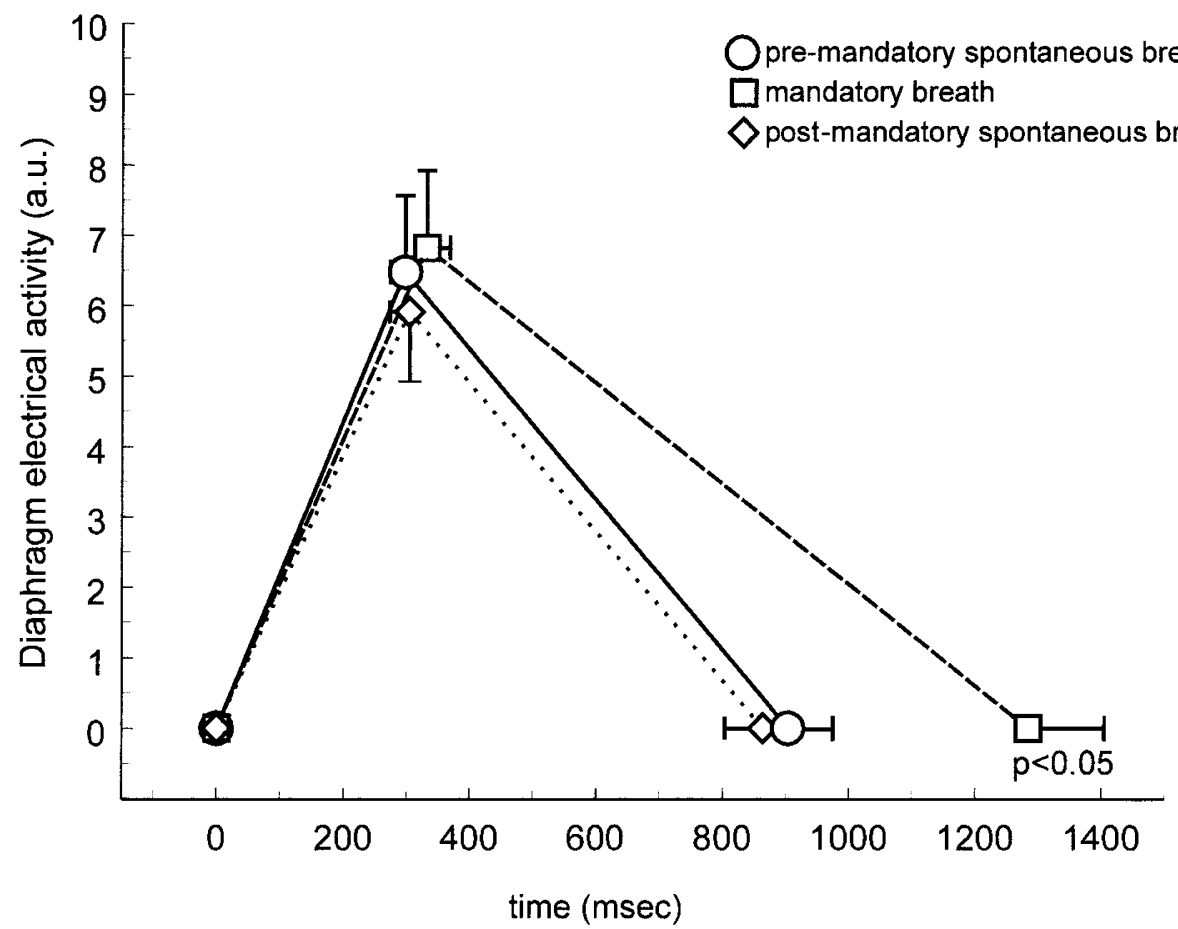

Figure 3. EAdi-time profile for group mean data. Data are presented for group mean values \pm SEM. There was no significant difference in neural timing and EAdi amplitude on inspiration for the premandatory spontaneous breaths (solid line), mandatory breaths (dashed line), or postmandatory spontaneous breaths (dotted line). Neural Te was prolonged significantly for the mandatory breaths (dashed line). Note that this is not a representation of the shape of the EAdi recruitment pattern, but simply a representation of three points: the onset of EAdi, the peak of EAdi, and the onset of the EAdi for the subsequent breath.

present during every mandatory breath and constituted on average $53.4 \pm 26.2 \%$ of the total breath duration. Figure 4 represents these findings schematically.

The relative increase in neural Te during mandatory breaths (see formula in the "Methods" section) was related to the time that the ventilator inflated during neural Te (i.e. the time that the ventilator continued to inflate after the end of neural $\mathrm{Ti} ; r^{2}$ $=0.66 ; p=0.01 ;$ Fig. 5 ). In contrast, the relative increase in neural Te during mandatory breaths was not related to the extra volume delivered by the ventilator (i.e. the volume above the spontaneous volume; $\left.r^{2}=0.42 ; p=0.258\right)$.

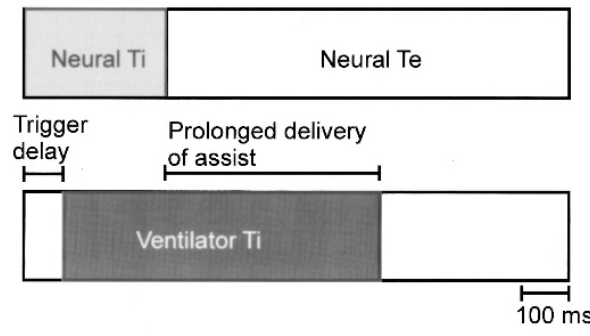

Neural timing

Ventilator timing

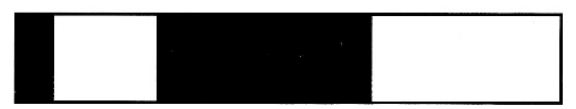

Asynchrony $(53 \%)$

Synchrony $(47 \%)$

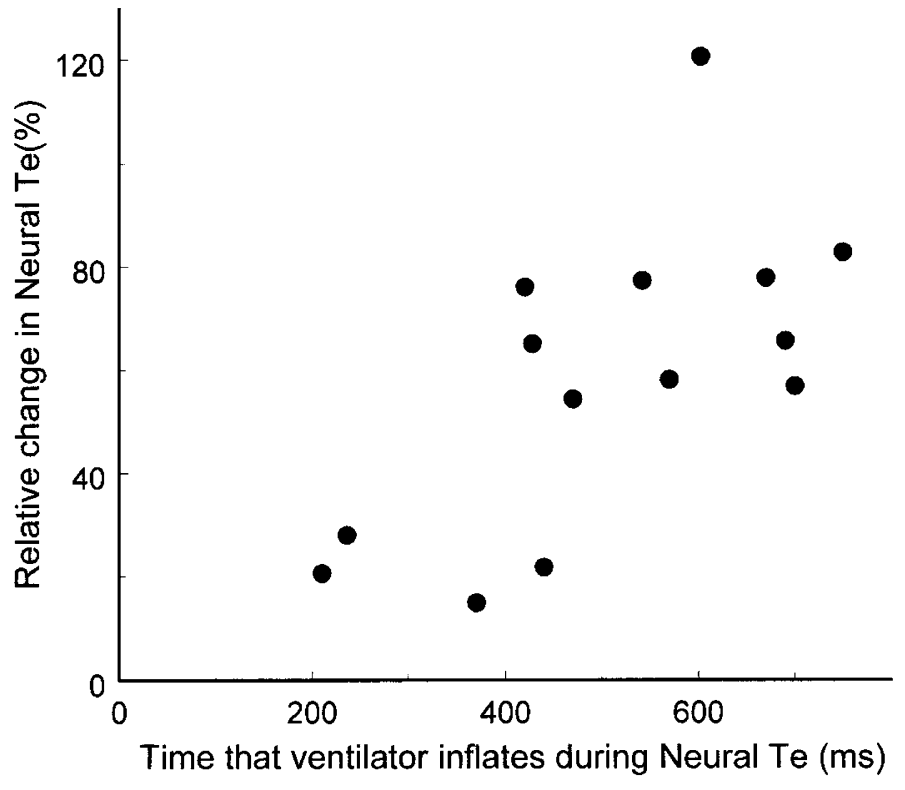

Figure 5. Relationship between change in neural $\mathrm{Te}$ and time that ventilator inflation coincides with neural expiration. For the 14 patients studied, figure shows relationship between the relative change in neural Te for the mandatory breaths (from the neural Te of the preceding spontaneous breath; $y$ axis) and the time that the ventilator delivers pressure during the neural Te period ( $x$ axis).

The coefficients of variation for neural $\mathrm{Ti}$, neural Te, mean EAdi, and baseline-to-peak EAdi are presented in Table 4. There was no significant difference in the coefficients of variation for the premandatory spontaneous breaths, and the mandatory and postmandatory spontaneous breaths.
Figure 4. Patient-ventilator interaction during mandatory breaths. Schematic representation of patient neural timing (upper bar) and ventilator timing (middle bar) during mandatory breaths. Upper bar, neural Ti (gray area) and neural Te (white) for the group data are presented. Middle bar, periods describing ventilator timing are displayed, including trigger delay and ventilator Ti. Bottom bar, periods of infant-ventilator synchrony (white) and asynchrony (black). 
Table 4. Factor variability expressed as coefficient of variation for the premandatory spontaneous breaths, mandatory breaths, and postmandatory spontaneous breaths

\begin{tabular}{|c|c|c|c|}
\hline & \multicolumn{3}{|c|}{ Coefficient of variation (\%) } \\
\hline & Premandatory breath & Mandatory breath & Postmandatory breath \\
\hline Neural Ti & $30.1 \pm 6.9$ & $31.2 \pm 15.7$ & $27.6 \pm 7.9$ \\
\hline Neural Te & $24.2 \pm 7.8$ & $26.7 \pm 10.2$ & $22.0 \pm 10.2$ \\
\hline XEAdi & $25.3 \pm 8.3$ & $29.8 \pm 19.6$ & $24.0 \pm 11.0$ \\
\hline$\Delta$ EAdi & $31.7 \pm 5.2$ & $39.4 \pm 16.7$ & $36.5 \pm 4.4$ \\
\hline
\end{tabular}

Abbreviations used: XEAdi, mean amplitude of inspiratory EAdi;

$\Delta$ EAdi, baseline to peak of inspiratory EAdi.

\section{DISCUSSION}

Summary of findings. The results of this study provide evidence for an expiratory prolongation reflex elicited during mechanical ventilation in the SIMV mode in infants. This reflex is confined to the mandatory breath, and does not carry over to the next, postmandatory spontaneous breath. The extent of expiratory prolongation was related to the time that the ventilator delivered assist during neural expiration. Despite these findings, there was no reduction in the mandatory breath neural Ti nor was there reduction in diaphragm activity when mandatory breaths were delivered. This suggests that the anticipated inspiratory-inhibiting reflex was not elicited by SIMV. During the mandatory breaths, there was significant asynchrony between the infant's neural timing and the ventilatory timing.

Critique of methods. To our knowledge, this is the first study to use EAdi for the evaluation of neural timings and diaphragm activation during lung inflation in infants. Consequently, it is important to discuss the reliability of this technique. The EAdi signal strength is dependent on accurate methodology for acquisition (i.e. electrode configuration), analysis (7), and electrode positioning (11). With this technology, electrode configuration has been validated $(7,12)$, and changes in muscle to electrode distance are accounted for (7, 8) - this solution is of critical importance in the EAdi measurements of infants who have large posterior (caudal) displacement of the diaphragm during tidal breathing (13). The EAdi signal strength is also influenced by factors affecting signal quality, such as cardiac activity, electrode motion artifacts, and noise, technical problems that have been overcome $(9,10,14)$. A frequently recurring criticism of the measurement of EAdi with esophageal or implanted electrodes during spontaneous breathing is that the signal strength is affected by changes in muscle length or lung volume. This critique is based on studies of evoked diaphragm compound muscle action potentials (15) or outdated methodology that does not control for interelectrode distance (16). Using appropriate methodology, EAdi obtained during spontaneous breathing is not artifactually influenced by changes in muscle length, chest wall configuration, or lung volume $(17,18)$.

The HB expiratory-promoting reflex was originally characterized in animals by a prolongation of the expiratory period (apnea) after maintained lung expansion at end inspiration (2). This "end-inspiratory occlusion" (sustained inflation) technique is still used today to evaluate the HB expiratorypromoting reflex in infants (19-21). This method has been said, however, to offset the vagally mediated effects by the hypoxic and hypercapnic stimuli that gradually build during the ventilatory inhibition (i.e. occlusion) $(22,23)$. Rapid lung inflation is an alternative approach to evaluate the expiratorypromoting reflex in infants (1), but this method has also been criticized because of claims that the duration of the resultant apnea was dependent on the chemical composition of the inflation gas (23). On the one hand, in the present study, the SIMV mode of mechanical ventilation provided the model of rapid lung inflation. [And in this case, we believe that the chemical composition of the delivered gas (e.g. the fraction of inspired oxygen) during the rapid lung inflation (mandatory breaths) was the same as the control breath (premandatory and postmandatory spontaneous breaths in this model.] On the other hand, because of the poor interaction between the baby's neural breathing pattern and the delivery of assist, the SIMV mode can also be considered a model of end-inspiratory occlusion (assist was being delivered during neural expiration and an elevated lung volume was maintained). In response to the critique of the method described above, we do not believe that any hypoxic or hypercapnic stimuli could have influenced the reflex during this period of overinflation (times ranged from 210 to $750 \mathrm{~ms}$ ).

Comparison with previous findings. In terms of the expiratory-promoting reflex, studies have shown that vagal stimulation imposed during early expiration in anesthetized animals prolongs the expiratory time of the perturbed cycle $(24,25)$. Both Clark and von Euler (26) and Knox (24) showed in animals that the responsiveness of Te prolongation was increased when pulse inflations were delivered further into expiration. It has been demonstrated that there is a timedependence to this response and that when ventilator breaths were delivered in the last quartile of expiration, Te remained unchanged $(24,27)$. Our findings of an augmentation in neural $\mathrm{Te}$ in all infants (range, 14-83\%) during the mandatory breaths and the fact that the relative increase in neural Te during the mandatory breath was positively correlated to the duration of ventilatory assist during neural Te (Fig. 5) is consistent with the above findings, and supports the notion that SIMV can induce a vagally mediated expiratory-promoting reflex. A similar relationship to that described in Figure 5 was recently reported using an indirect mechanical index of muscle activation in mechanically ventilated adult patients with acute lung injury (28), suggesting that mechanical ventilation can also elicit this reflex in adults. 
Further evidence that the reflex response in neural Te was confined to the mandatory breath was the fact that the effect did not carry over to the postmandatory spontaneous breath neural $\mathrm{Te}$, which was similar to the premandatory spontaneous breath neural Te. Although the data were not shown, Satoh et al. (27) also claimed that single ventilator-delivered breaths affected the timing only of the perturbed breath, and not the subsequent spontaneous breath.

Implications for reflex control of breathing pattern by lung inflation. Why should the HB expiratory-promoting reflex occur without the inspiratory-inhibiting reflex? The HB inspiratory-inhibiting reflex is usually studied in infants by comparing inspiratory duration of a control breath (Ti measured from Pao) to the $\mathrm{Ti}$ of the inspiratory effort during airway occlusion at end expiration $(29,30)$. With surface electromyography of the diaphragm, Witte and Carlo (31) demonstrated in tracheostomized children a clear prolongation in neural $\mathrm{Ti}$ (with similar rate of rise of the EAdi) for occluded efforts at end-expiratory lung volume, compared with spontaneous, unoccluded breaths. A lengthening of the occluded effort presumably reflects the removal of afferent signals of lung expansion. In effect, this is a loading technique (i.e. occlusion) used to examine the reflex. Mechanical ventilation, which can be considered an unloading technique, should therefore follow the reverse, i.e. that inflation by the ventilator should result in an earlier attainment of the volume threshold for inspiratory termination, and a reduction in neural Ti. We expected to observe this effect in our infants, as demonstrated by Younes et al. (32) in cats during ventilatory assist. However, our data showed neither changes in neural Ti nor a decrease in EAdi amplitude during the mandatory breaths when compared with premandatory and post mandatory spontaneous breaths.

The delay between the onset of neural $\mathrm{Ti}$ and the onset of ventilatory support was $95 \mathrm{~ms}$ or approximately $29 \%$ of neural Ti. This delay can be explained by 1 ) the patient's neuroventilatory coupling process (defined as the time between the onset of diaphragm activation to the onset of flow generation) (10), 2) the "trigger delay," which includes the time to recognize an inspiratory change and send a trigger signal to the ventilator, and 3) the "system delay," which is the time from the trigger signal until the onset of positive pressure in the endotracheal tube (approximately $25 \mathrm{~ms}$ according to the manufacturers). Considering that eight of the 14 patients had bronchiolitis and were likely hyperinflated, it could be speculated that the neuroventilatory uncoupling (transformation of onset of neural activity into onset of airway flow at the endotracheal tube) contributed to the total delay.

The delay we observed constitutes a significant inspiratory asynchrony between the patient and the ventilator; only the last $230 \mathrm{~ms}$ (approximately 71\%) of neural $\mathrm{Ti}$ was associated with ventilator inflation. We suggest, therefore, that there was insufficient time to elicit the inspiratory-inhibiting reflex because the threshold for triggering the inspiratory-inhibiting reflex progressively increases during inspiration (26).

This timing discrepancy may also explain why Imsand et al. (33), in adult patients with chronic obstructive pulmonary disease, found no evidence for an inspiratory-inhibiting reflex during mandatory breaths in SIMV, i.e. no instantaneous change in neural Ti and EAdi amplitude. In that study, patients with chronic obstructive pulmonary disease were studied and the mandatory breaths were pressure-triggered, with trigger levels set at -1 to $-2 \mathrm{~cm} \mathrm{H}_{2} \mathrm{O}$. Only two of the five subjects studied were ventilated with applied positive end-expiratory pressure. Therefore, there was likely a considerable delay between the onset of neural activity and the onset of delivered assist for the mandatory breath in the work of Imsand et al. (33). It can be hypothesized, therefore, that if a synchronized mode of mechanical ventilation were to be implemented (i.e. matching the initiation and termination of ventilatory assist with the patient's neural timing), the opposite findings of our study would have been obtained, i.e. 1) elicitation of the inspiratory-inhibiting reflex, as demonstrated by Younes et al. (32) with a phrenic nerve-controlled (synchronized) respirator, and 2) no elicitation of the expiratory-promoting reflex (if the ventilator is cycled off neurally).

Further evidence for a contrast between the two components of the HB inflation reflex (i.e. the absence of the inspiratoryinhibiting reflex and presence of the expiratory-prolonging reflex) has been observed in animal studies. Clark and von Euler (26) found that subthreshold inflations, which were able to prolong expiration, were without effect during inspiration. In the present study, however, we obtained volume measurements from the ventilator in nine patients. Despite significantly greater volumes for the mandatory breaths (compared with the premandatory spontaneous breaths), we can only speculate that these greater volumes were not sufficiently timed with the patient's neural inspiration to elicit the inspiratory-inhibiting reflex, but could still elicit the expiratory-promoting reflex. In summary, on the basis of the literature and the present findings, it still remains to be shown that the HB inspiratory-inhibiting reflex is elicited by mechanical ventilation in infants.

Clinical implications. Although not frequently used in adults (34), SIMV is still frequently used as a tool for providing support and for weaning from mechanical ventilation in the infant setting (35). It was originally thought that delivery of the mandatory breath would reflexly deactivate the inspiratory muscles, and that the SIMV mode would allow the combination of unassisted breathing with respiratory muscle rest (36). The present study shows in infants, similar to the findings of Imsand et al. (33) in adults, that there is no reflex deactivation of the diaphragm during the delivery of the mandatory breaths. However, neither the study of Imsand et al. (33) nor the present study used modes of mechanical ventilation in which patient and ventilator timings were matched.

In the present work, infant-ventilator asynchrony was present in every mandatory breath and consisted of $53 \%$ of the total breath duration (inspiratory and expiratory asynchrony combined). Most of the infant-ventilator asynchrony was associated with expiratory asynchrony, in which the ventilator continued to deliver assist despite the fact that diaphragm activation was decreasing. According to the literature, there are severe consequences of expiratory asynchrony, the most important being that active exhalation against positive-pressure inflation develops pneumothoraces (37), barotrauma $(3,38)$, and cerebral blood flow fluctuations, which can be associated with intraventricular hemorrhage (39). In extreme cases of 
expiratory asynchrony, use of sedation or muscle paralysis is sometimes necessary $(38,40,41)$. In the adult literature, it is clear that poor off-cycling of mechanical ventilation results in an increased work of breathing (42) and patient discomfort (43). The present work therefore highlights the importance of online monitoring of diaphragm activation during mechanical ventilation, particularly with respect to the adjustment of cycling off ventilatory assist.

Variability in breathing pattern. There are no reports in the literature concerning the variability of timing and amplitude of EAdi in mechanically ventilated infants. Te and Ti measured via flow signals in nonmechanically ventilated preterm infants indicate a larger variability in $\mathrm{Te}(81 \%)$ than $\mathrm{Ti}(25 \%)(44)$. Our data show that there was no significant difference in the coefficients of variation for neural Ti and neural Te. Moreover, there were no significant differences of variability in all measurements for the three breath conditions (premandatory spontaneous breaths, mandatory breaths, and postmandatory spontaneous breaths). On the basis of the observation of a high variability in diaphragm activation variables, in addition to the instantaneous changes in breathing pattern reflexly caused by overinflation, one could consider the importance of recently developed modes of mechanical ventilation that adapt on a breath-to-breath basis to changes in respiratory drive (e.g. proportional assist ventilation and neurally adjusted ventilatory assist) (45).

Acknowledgments. The authors thank M. Norman Comtois, M. Sylvain Morneau, R.T., and Mlle Roxanne Trahan, R.N., for their help during the studies. We also thank Dr. Jim Duffin for his comments on the manuscript.

\section{REFERENCES}

1. Cross KW, Klaus M, Tooley WH, Weisser K 1960 The response of the new-born baby to inflation of the lungs. J Physiol (Lond) 151:551-565

2. Hering E, Breuer J 1868 Die Selbststeurung der athmung durch den nervus vagus. Sitzber Deut Akad Wiss Wein 57:672-677

3. Greenough A, Morley C, Davis J 1983 Interaction of spontaneous respiration with artificial ventilation in preterm babies. J Pediatr 103:769-773

4. Giffin F, Greenough A, Naik S 1996 The Hering-Breuer reflex in ventilated children. Respir Med 90:463-466

5. Carlo WA, Ambalavanan N 1999 Conventional mechanical ventilation: traditional and new strategies. Pediatr Rev 20:e117-e126

6. Parthasarathy S, Jubran A, Tobin MJ 2000 Assessment of neural inspiratory time in ventilator-supported patients. Am J Respir Crit Care Med 162:546-552

7. Beck J, Sinderby C, Lindström L, Grassino A 1996 Influence of bipolar esophageal electrode positioning on measurements of human crural diaphragm EMG. J Appl Physiol 81:1434-1449

8. Sinderby C, Beck J, Lindström L, Grassino A 1997 Enhancement of signal quality in esophageal recordings of diaphragm EMG. J Appl Physiol 82:1370-1377

9. Sinderby C, Beck J, Weinberg J, Spahija J, Grassino A 1998 Voluntary activation of the human diaphragm in health and disease. J Appl Physiol 85:2146-2158

10. Sinderby C, Navalesi P, Beck J, Skrobik Y, Comtois N, Friberg S, Gottfried SB, Lindström L 1999 Neural control of mechanical ventilation in respiratory failure. Nat Med 5:1433-1436

11. Beck J, Sinderby C, Weinberg J, Grassino A 1995 Effects of muscle-to-electrode distance on the human diaphragm electromyogram. J Appl Physiol 79:975-985

12. Sinderby CA, Comtois AS, Thomson RG, Grassino AE 1996 Influence of the bipolar electrode transfer function on the electromyogram power spectrum. Muscle Nerve 19:290-301

13. Laing IA, Teele RL, Stark AR 1988 Diaphragmatic movement in newborn infants. J Pediatr 112:638-643

14. Sinderby C, Lindstrom L, Grassino AE 1995 Automatic assessment of electromyogram quality. J Appl Physiol 79:1803-1815
15. Gandevia SC, McKenzie DK 1986 Human diaphragmatic EMG: changes with lung volume and posture during supramaximal phrenic stimulation. J Appl Physiol 60:1420-1428

16. Brancatisano A, Kelly SM, Tully A, Loring SH, Engel LA 1989 Postural changes in spontaneous and evoked regional diaphragmatic activity in dogs. J Appl Physiol 66:1699-1705

17. Beck J, Sinderby C, Lindström L, Grassino A 1998 Effects of lung volume on diaphragm EMG signal strength during voluntary contractions. J Appl Physiol $85: 1123-1134$

18. Sinderby C, Lindström L, Comtois N, Grassino AE 1996 Effects of diaphragm shortening on the mean action potential conduction velocity. J Physiol (Lond) 490:207-214

19. Brown K, Stocks J, Aun C, Rabette PS 1998 The Hering-Breuer reflex in anesthetized infants: end-inspiratory vs. end-expiratory occlusion techniques. J Appl Physiol 84:1437-1446

20. Rabbette PS, Stocks J 1998 Influence of volume dependency and timing of airway occlusions on the Hering-Breuer reflex in infants. J Appl Physiol 85:2033-2039

21. Hassan A, Gossage J, Ingram D, Lee S, Milner D 2001 Volume of activation of the Hering-Breuer inflation reflex in the newborn infant. J Appl Physiol 90:763-769

22. Merazzi D, Mortola J 1999 Hering-Breuer reflex in conscious newborn rats: effects of changes in ambient temperature during hypoxia. J Appl Physiol 87:1656-1661

23. Younes M, Vaillancourt P, Milic-Emili J 1974 Interaction between chemical factors and duration of apnea following lung inflation. J Appl Physiol 36:190-201

24. Knox CK 1973 Characteristics of inflation and deflation reflexes during expiration in cats. J Neurophysiol 36:284-295

25. Sammon M, Romaniuk JR, Bruce EN 1993 Bifurcations of the respiratory pattern produced with phasic vagal stimulation in the rat. J Appl Physiol 75:912-926

26. Clark FJ, von Euler C 1972 On the regulation of depth and rate of breathing. J Physiol (Lond) 222:267-295

27. Satoh M, Eastwood PR, Smith CA, Dempsey JA 2001 Nonchemical elimination of inspiratory motor output via mechanical ventilation in sleep. Am J Respir Crit Care Med 163:1356-1364

28. Kondili E, Prinianakis G, Anastasaki M, Georgopoulos D 2001 Acute effects of ventilator settings on respiratory motor output in patients with acute lung injury. Intensive Care Med 27:1147-1157

29. Bryan AC, Bryan MH, Kirkpatrick SM, Knill RL 1976 The use of airway occlusion in infants. Chest 70:142-145

30. Olinsky A, Bryan MH, Bryan AC 1974 Influence of lung inflation on respiratory control in neonates. J Appl Physiol 36:426-429

31. Witte MK, Carlo W 1987 Prolongation of inspiration during lower airway occlusion in children. J Appl Physiol 62:1860-1864

32. Younes M, Baker JP, Polachek J, Remmers JE 1978 Termination of inspiration through graded inhibition of inspiratory activity. Adv Exp Med 99:383-395

33. Imsand C, Feihl F, Perret C, Fitting JW 1994 Regulation of inspiratory neuromuscular output during synchronized intermittent mechanical ventilation. Anesthesiology $80: 13-22$

34. Esteban A, Anzueto A, Alia I, Gordo F, Apezteguia C, Palizas F, Cide D, Goldwaser R, Soto L, Bugedo G, Rodrigo C, Pimentel J, Raimondi G, Tobin MJ 2000 How is mechanical ventilation employed in the intensive care unit? Am J Respir Crit Care Med 161:1450-1458

35. Imanaka H, Nishimura M, Miyano H, Uemura H, Yagihara $T 2001$ Effect of synchronized intermittent mandatory ventilation on respiratory workload in infants after cardiac surgery. Anesthesiology 95:881-888

36. Sassoon C 1994 Intermittent mandatory ventilation. In: Tobin MJ (ed) Principles and Practice of Mechanical Ventilation. McGraw Hill, New York, pp 221-238

37. Greenough A, Milner AD, Dimitriou G 2001 Synchronized mechanical ventilation for respiratory support in newborn infants. Cochrane Database Syst Rev 1:CD000456

38. Greenough A, Wood S, Morley CJ, Davis JA 1984 Pancuronium prevents pneumothoraces in ventilated premature babies who actively expire against positive pressure ventilation. Lancet $1: 1-13$

39. Lipscomb AP, Thorburn RJ, Reynolds EO, Blackwell RJ, Stewart AL, Blackwell RJ, Cusick G, Whitehead MD 1981 Pneumothorax and cerebral haemorrhage in preterm infants. Lancet 1:414-416

40. Henry GW, Stevens CS, Schreiner RL, Grosfeld JL, Ballantine TV 1979 Respiratory paralysis to improve oxygenation and mortality in large newborn infants with respiratory distress. J Pediatr Surg 14:761-766

41. Stark AR, Bascom R, Frantz ID 1978 Muscle relaxation in mechanically ventilated infants. J Pediatr 94:439-443

42. Tokioka H, Tanaka T, Ishizu T, Fukushima T, Iwaki T, Nakamura Y, Kosogabe Y 2001 The effect of breath termination criterion on breathing patterns and the work of breathing during pressure support ventilation. Anesth Analg 92:161-165

43. Calderini E, Confalonieri M, Puccio PG, Francavilla N, Stella L, Gregoretti C 1999 Patient-ventilator asynchrony during noninvasive ventilation: the role of expiratory trigger. Intensive Care Med 25:662-667

44. Al-Hathlol K, Idiong N, Hussain A, Kwiatkowski K, Alvaro RE, Weintraub Z, Cares DB, Rigatto H 2000 A study of breathing pattern and ventilation in newborn infants and adult subjects. Acta Paediatr 89:1420-1425

45. Navalesi P, Costa R 2003 New modes of mechanical ventilation: proportional assist ventilation, neurally adjusted ventilatory assist, and fractal ventilation. Curr Opin Crit Care 9:51-58 